\title{
Infants' emotional states influence maternal behaviors during holding
}

\author{
by \\ Yumiko Nishimura $^{1}$ \\ Yasuhiro Kanakogi ${ }^{1}$ \\ Masako Myowa-Yamakoshi ${ }^{1}$ \\ ${ }^{1}$ Graduate School of Education, Kyoto University
}

Address correspondence to:

Yumiko Nishimura

Graduate School of Education,

Kyoto University

Yoshida-honmachi, Sakyo-ku, Kyoto, 606-8501, JAPAN

Email: yumi0817n@gmail.com 


\begin{abstract}
Previous studies have mainly examined how maternal behaviors influence infants during holding. However it is unclear how infants influence maternal holding. This current study investigated how infants' emotional states influence maternal holding behaviors, and whether maternal holding behaviors are also influenced by the mothers' parenting stress. We manipulated infants' emotional states and videotaped mothers' holding behaviors. The mothers also completed a questionnaire about their parental stress. Results showed that mothers varied their holding behaviors depending on their infants' emotional states. When infants were comfortable, mothers rocked them horizontally and quietly. When infants were uncomfortable, mothers rocked them vertically at a high frequency. Furthermore, some types of parenting stress were related to several types of maternal behaviors in the context of holding. These findings suggest that maternal holding behaviors are influenced by both the infants' emotional states and the mothers' parenting stress.
\end{abstract}

(141 words)

Keywords: mother-infant interaction, holding, emotion, parenting stress 


\section{Introduction}

Mothers and infants show a great variety of interactions, such as holding, touching, playing, and vocalizing. Mother-infant interactions are important because they provide the foundation for attachment and the cognitive development of infants (Cogill, Caplan, Alexandra, Robson, \& Kumar, 1986; Lewis \& Feiring, 1989; Murray, Fiori-Cowley, Hooper, \& Cooper, 1996). One basic mother-infant interaction involves touching. Touching regulates the emotions of infants or attracts the attention of infants (Gray, Watt, \& Blass, 2000; Stack \& Muir, 1992). Ferber, Feldman, and Makhoul (2008) showed that affective touching promoted dyadic reciprocity, such as give-and-take interactions, sharing activities, or adapting to mutual needs. Moreover, touching is associated with secure attachment, mental and psychomotor development, and maternal sensitivity (Feldman, Eidelman, Sirota, \& Weller, 2002; Weiss, Wilson, Hertenstein, \& Campos, 2000). Through affective touching, especially during holding, mothers and infants influence each other as part of the process of maintaining stable contact. Negayama et al. (2010) point out that caregivers could transport, nurse, protect and love their infants through holding, so holding is an essential component in mother-infant interactions.

Regarding the influence of mothers, Saijo and Negayama (2001) reported that mothers' body postures during holding make infants change their behaviors. When mothers were standing or walking, infants clung to their mothers or their mothers' clothing using their arms or legs. Esposito et al. (2013) showed that maternal holding accompanying walking made infants calm down. Infants held by walking mothers decreased their voluntary movements, crying, and heart rates. The authors considered 
that these behaviors made it easier for the mothers to carry their infants. Reddy, Markova, and Wallot (2013) observed infants' responses while being picked up by mothers. Three-month-old infants adjusted the position of their body parts, such as widening arms, raising arms, or extending legs, in response to the approach of their mother. Mothers' body postures and movements during holding may influence infants' movements or emotional states.

Conversely, do infants' movements and emotional states influence mothers during holding? Jean and Stack (2009) found that mothers changed the amount of nurturing touch according to their infant's distress level. Aso and Iwatate (2006) pointed out that mothers showed different types of touching related to different parenting situations (e.g., playing, infant crying, putting infant to sleep, bathing etc.). For example, in a playing context, mothers used strong physical stimulation (e.g., shaking hands, poking, tickling, and rough rocking). When the infant was crying, mothers used rhythmic touching (e.g., moderate rocking, tapping, and stroking). This finding indicates that maternal behaviors may vary depending on infants' emotional states related to parenting situations. However, it is still unclear how infants' emotional states influence maternal holding. In the present study, we investigated how maternal holding behaviors are influenced by infants' emotional states.

In addition, we focused on the relationship between parenting stress and mothers' holding behaviors. Previous studies have suggested that mothers with depression or maternity blues show specific parenting behaviors (e.g., Ferber, 2004; Malphurs, Raag, Field, Pickens, \& Pelaez-Nogueras, 1996; Paulson, Dauber, \& Leiferman, 2006; Væver, Krogh, Smith-Nielsen, Harder, \& Køppe, 2013). For example, mothers with depression had fewer interactions with their infants, or touched their infants roughly, such as 
stimulating touching and shaking. These findings raise the possibility that, even in healthy mothers, parenting stress can influence their parenting behaviors. Thus, we examined the relationship between parenting stress and holding behaviors in healthy mothers with no depression.

In the current study, we hypothesized that (a) infants' emotional states would influence maternal holding behaviors, and (b) parenting stress would relate to the types of mothers' holding behaviors.

\section{Method}

\subsection{Participant}

The participants were 25 six-month-old infants ( 13 females, $M=27.93$ weeks, $S D$ $=1.42)$ and their mothers $(M=33.32$ years, $S D=4.00)$. An additional 10 pairs of mothers and infants were excluded from analysis because of the fussiness of the infants. This study was approved by the Ethic Committee of Kyoto University (26-P-3). The study was conducted in accordance with the standards specified in the 1964 Declaration of Helsinki. Before the experiment, each mother provided written informed consent.

\subsection{Measures}

\subsubsection{Parenting stress}

The Japanese version of the Parenting Stress Index (PSI) was used to assess parenting stress (Abidin, 1995; Hanada, Honda, Tokumaru, \& Ozawa, 2006; Narama et 
al., 1999). This questionnaire consists of 78 self-report items (rated on a 4 or 5-point scale), comprising two subscales: stress regarding the child and stress regarding the parents. The subscale of stress regarding the child included C-1 (The child provides few responses that make the parents happy), C-2 (The child is in a bad mood), C-3 (The child is not the way I expected), C-4 (The child cannot concentrate/is hyperactive), C-5 (The child follows the parent/has a hard time getting used to others), C-6 (I think that the child is problematic), and C-7 (The child is sensitive to stimulation/has a hard time getting used to things). The subscale of stress regarding the parents included P-1 (Restrictions due to parental roles), P-2 (Social isolation), P-3 (The relationship with the spouse), P-4 (Parental capability), P-5 (Depression/sense of guilt), P-6 (Feelings after being discharged from the hospital), P-7 (I can hardly feel affection for my child), and P-8 (Health status)

\subsubsection{Infant heart rate measure}

During the experiment, the heart rate (HR) of the infants was measured. A wireless NeXus-10 device (MindMedia B.V., Netherlands) was used to obtain electrocardiogram data. The sampling rate was $1024 \mathrm{~Hz}$. Three electrodes were placed on the body surface around both collar bones and the left rib. When mothers held their infants, a wireless NeXus-10 device was in the mother's waist pack. Mean HR was calculated by detecting peaks of the R-wave using the software, Biotrace+ (MindMedia B.V., Netherlands) and BIMUTAS II (KISSEI COMTEC, Japan).

\subsection{Procedure}


The mother and infant participants were brought into the study room, which was softly illuminated. The mother gave her written informed consent for participating in the study. Experimenters developed a rapport with the infant by playing using toys for about 10 minutes and the experiment was started after the experimenters judged that the infant had become habituated to the experimenters and the room. The heart rate monitoring equipment was attached to the infant, who sat in an infant seat. The mother sat next to her infant. The mother was instructed to sit still and watch a scenery video with her infant (the baseline period). One infant sat on the mother's lap because this infant was unwilling to sit in the infant seat. Following the baseline period, there were two experimental conditions (the comfortable and the uncomfortable conditions). First, in the comfortable condition, the mother was instructed to hold her infant while standing for 3 minutes as usual (the pre-holding period). Next, the infant sat in an infant seat and the mother played with her infant freely while sitting facing the infant for 3 minutes (the play period). The mother was allowed to touch her infant during the play period. Five infants sat on their mothers' laps because they were unwilling to sit in the infant seat. When infants were sitting on the lap, mothers supported their infants' bodies by using their arms while sitting. Then the mother was instructed to hold her infant for 3 minutes in the same way as usual (the post-holding period). After the comfortable condition, the mother filled out the questionnaire about parenting stress for about 15 minutes.

After that, the uncomfortable condition was started. In the uncomfortable condition, the mother was instructed to hold her infant for 3 minutes in the same way as usual (the pre-holding period). Next, the infant sat in an infant seat and the mother moved to a seat behind a partitioning screen, which concealed the mother from her infant (the separation period). Three minutes later, the mother was instructed to hold her 
infant for 3 minutes in the same way as usual (the post-holding period). When an infant began to cry within 3 minutes in the separation period, the infant was left for at least 30 seconds to expose the infant to a negative state. After that, the mother held her infant.

The order of two conditions (the comfortable condition and the uncomfortable condition) was fixed, since there was a high possibility that the uncomfortable state for the infant might make it impossible to continue with a following condition. The scenes of the mother holding her infant were videotaped from three directions.

\subsection{Coding of maternal behaviors during holding their infants}

The data from the first one minute of each condition were used for the analyses because the infants' emotional states in both conditions are the most salient at the start of the episodes. The presence or absence of each maternal behavior during the first one minute of both pre- and post-holding periods in both the comfortable and uncomfortable conditions was coded for each 1-s interval. We constructed a coding scale including 16 maternal behaviors based on Aso and Iwatate (2006).

For the analyses, we classified four main categories of maternal behaviors, further divided into 16 subcategories: Touching (stroking, grabbing, tapping, poking/pinching, and tickling), Rocking (rocking horizontally and quietly, rocking horizontally and roughly, rocking vertically at high frequency, rocking vertically and gently at low frequency, and rocking vertically and roughly at low frequency), Holding (horizontal holding, vertical holding, and lifting), and Other behaviors (shaking, vocalizing, and caretaking). The four categories were not mutually exclusive, but the subcategories included in each category were mutually exclusive, except for the subcategories of the 
Other behaviors category. A second coder also coded $20 \%$ of the maternal holding scenes. Because of the skewed distribution, the prevalence-adjusted and bias-adjusted kappa (PABAK; Byrt, Bishop, \& Carlin, 1993) was used. Definitions and inter-rater reliabilities (Cohen's kappa and PABAK) for each of the maternal behaviors are shown in Table1.

Furthermore, we calculated the frequency of transition to investigate the relationship between parenting stress and the frequency of transition of types of mothers' holding behaviors during the post-holding periods. The frequency of transition was defined as the number of transitions of subcategories within each category in which maternal behaviors were mutually exclusive. The Other behaviors category was not included in this analysis, since its subcategories were not mutually exclusive. 
Table 1

Definitions of categories of maternal behaviors

\begin{tabular}{|c|c|c|c|}
\hline Category & Definition & $\kappa$ & $\begin{array}{l}\text { PAB } \\
\text { AK }\end{array}$ \\
\hline \multicolumn{4}{|l|}{ Touching } \\
\hline T1: stroking & stroking part of infant's body, such as the infant's back or head & 0.67 & 1.00 \\
\hline T2: grabbing & grabbing or shaking infant's hand or leg & 0.77 & 0.99 \\
\hline T3: tapping & tapping part of infant's body, such as the infant's back or hip & 0.89 & 0.92 \\
\hline T4: poking/pinching & $\begin{array}{l}\text { poking or pinching part of infant's body, such as the infant's cheek or } \\
\text { nose }\end{array}$ & 0.66 & 0.99 \\
\hline T5: tickling & tickling part of infant's body, such as the infant's rib or leg & 0.87 & 1.00 \\
\hline \multicolumn{4}{|l|}{ Rocking } \\
\hline $\begin{array}{l}\text { R1: rocking } \\
\text { horizontally and } \\
\text { quietly }\end{array}$ & $\begin{array}{l}\text { rocking infant horizontally and quietly, back and forth, or left and right } \\
\text { (e.g., smoothly rocking like a cradle, without roughly rocking) }\end{array}$ & 0.82 & 0.85 \\
\hline $\begin{array}{l}\mathrm{R} 2 \text { : rocking } \\
\text { horizontally and } \\
\text { roughly }\end{array}$ & $\begin{array}{l}\text { rocking infant horizontally and roughly as mother twists her own body } \\
\text { at the waist or leans forward, or pulls the infant's head away from the } \\
\text { mother's body }\end{array}$ & 0.68 & 0.98 \\
\hline $\begin{array}{l}\text { R3: rocking vertically } \\
\text { at high frequency }{ }^{b}\end{array}$ & $\begin{array}{l}\text { rocking vertically at } 1 \mathrm{~Hz} \text { or more, sometimes with horizontal } \\
\text { movement }\end{array}$ & 0.61 & 0.84 \\
\hline $\begin{array}{l}\text { R4: rocking vertically } \\
\text { and gently at low } \\
\text { frequency }{ }^{c}\end{array}$ & $\begin{array}{l}\text { rocking vertically and gently at less than } 1 \mathrm{~Hz} \text { including a single } \\
\text { rocking movement, sometimes with horizontal movement }\end{array}$ & 0.61 & 0.98 \\
\hline $\begin{array}{l}\text { R5: rocking vertically } \\
\text { and roughly at low } \\
\text { frequency }{ }^{c}\end{array}$ & $\begin{array}{l}\text { rocking vertically at less than } 1 \mathrm{~Hz} \text { and roughly as mother pulls infant's } \\
\text { body away from the mother's body or infants' head was shook, } \\
\text { including a single rocking, sometimes with horizontal movement }\end{array}$ & $-^{\mathrm{a}}$ & 1.00 \\
\hline \multicolumn{4}{|l|}{ Holding } \\
\hline H1: vertical holding & holding infant in a vertical posture & $-^{\mathrm{a}}$ & 0.99 \\
\hline H2: horizontal holding & holding infant in a diagonal or horizontal posture & $-^{\mathrm{a}}$ & 0.99 \\
\hline \multicolumn{3}{|l|}{ Other behaviors } & 0.99 \\
\hline O1: shaking & $\begin{array}{l}\text { shaking the infant's body up and down, or back and forth, or left and } \\
\text { right using only mother's hands }\end{array}$ & 0.81 & 0.97 \\
\hline O2: vocalizing & vocalizing, such as talking, singing, or meaningless vocalization & 0.74 & 0.77 \\
\hline O3: caretaking & wiping the infant's nose or mouth & 0.75 & 0.98 \\
\hline
\end{tabular}

Note. $\kappa$ : Cohen's kappa

PABAK: the prevalence-adjusted and bias-adjusted kappa

${ }^{a}$ Kappa could not be calculated due to empty cells.

${ }^{\mathrm{b}}$ high frequency: $M=2.60, S D=0.40$ (range: $1.56-4.0 \mathrm{~Hz}$ )

${ }^{c}$ low frequency: $M=0.73, S D=0.18$ (range: $0.40-0.98 \mathrm{~Hz}$ )

\section{Results}


3.1. Heart rate of infants in the baseline period, the play period and the separation period

The heart rate data from five infants was excluded from this analysis because of equipment failure or experimenter error. A one-way repeated measures ANOVA was conducted on the infants' HR data as a factor of period (baseline, play, separation). Greenhouse-Geisser epsilon was used to correct for violation of sphericity in this analysis. Results showed a significant main effect of period, $F(1.43,27.12)=15.84, p$ $<.001$, partial $\eta^{2}=.46$, Greenhouse-Geisser epsilon $=.71$. Bonferroni post-hoc tests for multiple comparisons showed that the infants' HR in the separation period of the uncomfortable condition was significantly higher than the HR in the baseline period ( $p$ $=.001)$ and the HR in the play period of the comfortable condition $(p=.005)$. There was no significant difference between the HR in the play period of the comfortable condition and the HR in the baseline period (Figure 1). 


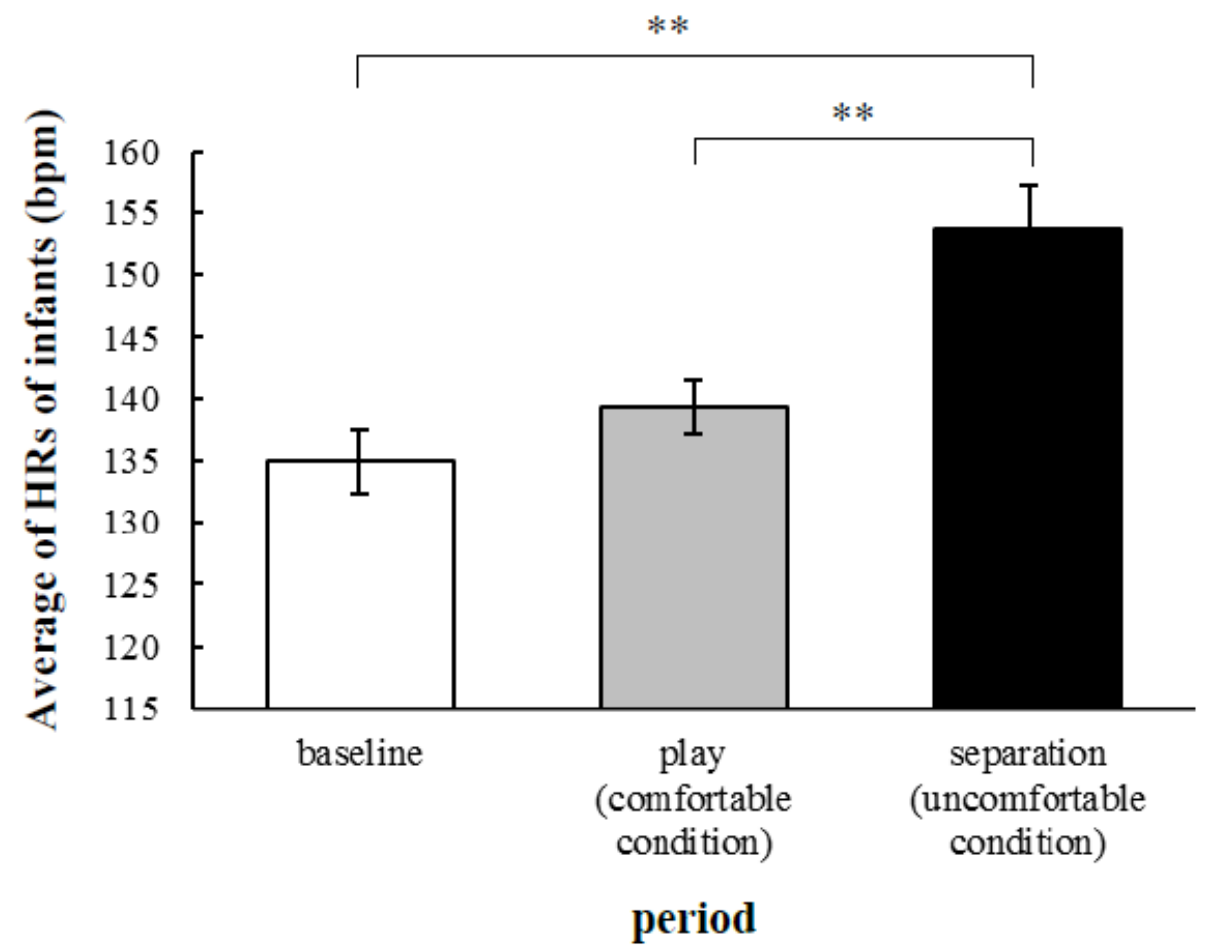

Figure 1. The average HRs of infants in the baseline period, the play period (comfortable condition), and the separation period (the uncomfortable condition). Error bars show SE. $* * p<.01$.

\subsection{Maternal behaviors during holding their infants}

\subsubsection{Maternal behaviors in the comfortable condition}

The durations of 'rocking horizontally and quietly' and 'vocalizing' in the post-holding period were significantly longer than in the pre-holding period in the comfortable condition (Wilcoxon Test: $z=-2.94, p=.003, r=-.59$ for 'rocking horizontally and quietly', and $z=-2.45, p=.014, r=-.49$ for 'vocalizing'). As for the durations of the other subcategories, no significant differences were found between the pre and the post-holding period in the comfortable condition (Table 2 and Figure 2). 
Table 2

Mean duration and standard deviations of maternal behaviors in the comfortable condition (sec)

\begin{tabular}{|c|c|c|c|c|c|}
\hline \multirow{2}{*}{ Category } & \multicolumn{2}{|c|}{ pre-holding } & \multicolumn{2}{|c|}{ post-holding } & \multirow{2}{*}{$p$} \\
\hline & $\mathrm{M}$ & $S D$ & $\mathrm{M}$ & $S D$ & \\
\hline \multicolumn{6}{|l|}{ Touching } \\
\hline T1: stroking & 0.60 & 1.87 & 0.48 & 1.16 & .931 \\
\hline $\mathrm{T} 2$ : grabbing & 0.32 & 1.60 & 0.12 & 0.60 & .655 \\
\hline T3: tapping & 15.84 & 17.14 & 11.44 & 15.65 & .079 \\
\hline T4: poking/pinching & 0.60 & 1.87 & 0.04 & 0.20 & .144 \\
\hline T5: tickling & 0.24 & 0.83 & 0.00 & 0.00 & .157 \\
\hline \multicolumn{6}{|l|}{ Rocking } \\
\hline $\begin{array}{l}\text { R1: rocking horizontally and } \\
\text { quietly }\end{array}$ & 28.44 & 22.82 & 39.36 & 17.72 & .003 \\
\hline $\begin{array}{l}\mathrm{R} 2 \text { : rocking horizontally and } \\
\text { roughly }\end{array}$ & 1.20 & 4.03 & 1.32 & 4.00 & 1.00 \\
\hline $\begin{array}{l}\text { R3: rocking vertically at high } \\
\text { frequency }\end{array}$ & 11.64 & 16.70 & 9.24 & 12.59 & .251 \\
\hline $\begin{array}{l}\text { R4: rocking vertically and } \\
\text { gently at low frequency }\end{array}$ & 1.12 & 3.82 & 0.36 & 1.32 & .416 \\
\hline $\begin{array}{l}\mathrm{R} 5 \text { : rocking vertically and } \\
\text { roughly at low frequency }\end{array}$ & 2.40 & 8.04 & 1.24 & 3.19 & .498 \\
\hline \multicolumn{6}{|l|}{ Holding } \\
\hline H1: vertical holding & 58.84 & 3.98 & 58.40 & 5.11 & .588 \\
\hline H2: horizontal holding & 0.00 & 0.00 & 0.12 & 0.60 & .317 \\
\hline H3: lifting & 1.64 & 5.11 & 1.76 & 5.58 & .892 \\
\hline \multicolumn{6}{|l|}{ Other Behaviors } \\
\hline O1: shaking & 2.40 & 5.17 & 1.80 & 4.33 & .261 \\
\hline O2: vocalizing & 17.36 & 15.25 & 22.28 & 15.40 & .014 \\
\hline O3: caretaking & 0.08 & 0.40 & 0.72 & 2.21 & .176 \\
\hline
\end{tabular}

Note. Statistic values indicate the results of Wilcoxon signed rank test comparing the pre-holding period and the post-holding period in the comfortable condition. 


\subsubsection{Maternal behaviors in the uncomfortable condition}

The durations of 'tapping', 'rocking vertically at high frequency' and 'vocalizing' in the post-holding period were significantly longer than in the pre-holding period in the uncomfortable condition (Wilcoxon Test: $z=-2.05, p=.040, r=-.41$ for 'tapping'; $z=$ $-2.09, p=.036, r=-.42$ for 'rocking vertically at high frequency'; paired $t$-test: $t(24)=$ $-2.38, p=.026, r=.44$ for 'vocalizing') . On the other hand, the duration of 'grabbing' in the post-holding period was significantly shorter than in the pre-holding period in the uncomfortable condition (Wilcoxon Test: $z=-2.24, p=.025, r=-.45$ ). However 'grabbing' was rarely observed in this study $(\mathrm{M}=2.12 \mathrm{sec}$ in the pre-holding period and $\mathrm{M}=0.20 \mathrm{sec}$ in the post-holding period). As for the durations of other subcategories, no significant differences were found between the pre and post-holding period in the uncomfortable condition (Table 3 and Figure 2). 
Table 3

Mean duration and standard deviations of maternal behaviors in the uncomfortable condition (sec)

\begin{tabular}{|c|c|c|c|c|c|}
\hline \multirow{2}{*}{ Category } & \multicolumn{2}{|c|}{ pre-holding } & \multicolumn{2}{|c|}{ post-holding } & \multirow{2}{*}{$p$} \\
\hline & $\mathrm{M}$ & $S D$ & $\mathrm{M}$ & $S D$ & \\
\hline \multicolumn{6}{|l|}{ Touching } \\
\hline T1: stroking & 2.76 & 6.69 & 1.20 & 4.11 & .195 \\
\hline $\mathrm{T} 2$ : grabbing & 2.12 & 4.85 & 0.20 & 1.00 & .025 \\
\hline T3: tapping & 9.60 & 15.38 & 14.64 & 16.23 & .040 \\
\hline T4: poking/pinching & 0.84 & 2.03 & 0.00 & 0.00 & .066 \\
\hline T5: tickling & 0.00 & 0.00 & 0.40 & 1.80 & .180 \\
\hline \multicolumn{6}{|l|}{ Rocking } \\
\hline $\begin{array}{l}\text { R1: rocking horizontally and } \\
\text { quietly }\end{array}$ & 41.04 & 16.64 & 38.12 & 16.69 & .432 \\
\hline $\begin{array}{l}\mathrm{R} 2 \text { : rocking horizontally and } \\
\text { roughly }\end{array}$ & 1.32 & 3.17 & 0.72 & 2.56 & .673 \\
\hline $\begin{array}{l}\text { R3: rocking vertically at high } \\
\text { frequency }\end{array}$ & 8.00 & 9.38 & 12.92 & 11.93 & .036 \\
\hline $\begin{array}{l}\text { R4: rocking vertically and } \\
\text { gently at low frequency }\end{array}$ & 0.28 & 1.40 & 0.16 & 0.80 & .655 \\
\hline $\begin{array}{l}\mathrm{R} 5 \text { : rocking vertically and } \\
\text { roughly at low frequency }\end{array}$ & 1.20 & 3.55 & 0.76 & 2.70 & .197 \\
\hline \multicolumn{6}{|l|}{ Holding } \\
\hline H1: vertical holding & 59.32 & 3.01 & 57.60 & 9.41 & .345 \\
\hline $\mathrm{H} 2$ : horizontal holding & 0.68 & 3.40 & 1.52 & 7.60 & .655 \\
\hline H3: lifting & 0.12 & 0.60 & 1.28 & 3.25 & .068 \\
\hline \multicolumn{6}{|l|}{ Other behaviors } \\
\hline O1: shaking & 1.64 & 3.58 & 1.56 & 4.09 & .723 \\
\hline O2: vocalizing & 23.64 & 16.93 & 27.92 & 14.70 & .026 \\
\hline O3: caretaking & 0.44 & 1.16 & 0.32 & 0.80 & .724 \\
\hline
\end{tabular}

Note. Statistic values indicate the results of paired $t$-test and Wilcoxon signed rank test comparing the pre-holding period and the post-holding period in the uncomfortable condition. 


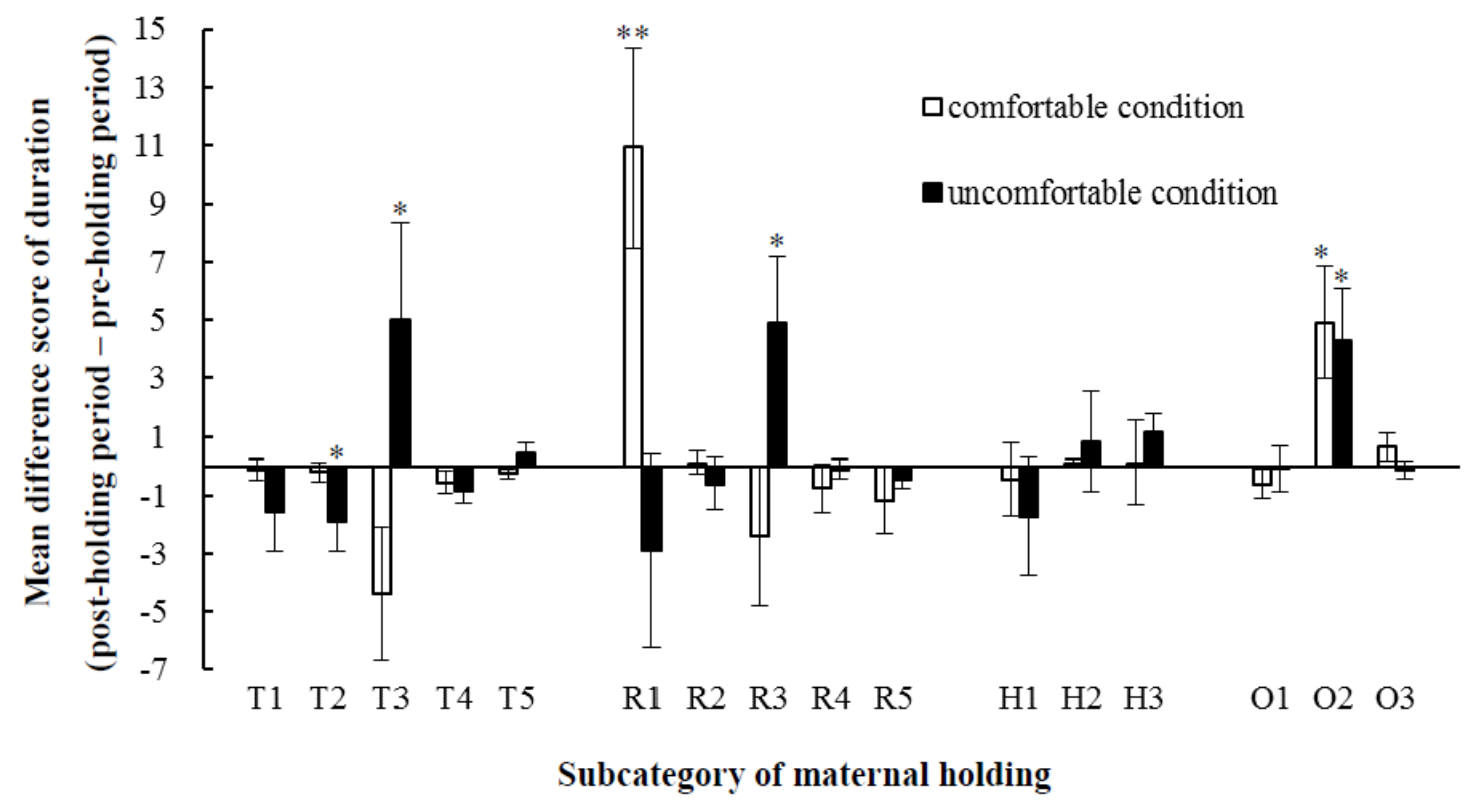

Figure 2. The mean difference scores of durations of subcategories (the post-holding period - the pre-holding period) in the comfortable and the uncomfortable condition. Touching (T1: stroking, T2: grabbing, T3: tapping, T4: poking/pinching, and T5: tickling); Rocking (R1: rocking horizontally and quietly, R2: rocking horizontally and roughly, R3: rocking vertically at high frequency, R4: rocking vertically and gently at low frequency, and R5: rocking vertically and roughly at low frequency); Holding (H1: horizontal holding, H2: vertical holding, and H3: lifting); Other behaviors (O1: shaking, O2: vocalizing, and O3: caretaking). Error bars show SE. ${ }^{*} p<.05 . * * p<.01$. 


\subsubsection{The amount of change in heart rate of infants in the two conditions}

In order to examine the holding effect we analyzed whether the infants' HRs changed from the play period or the separation period to the post-holding period. HR data for five infants from both the comfortable and uncomfortable conditions was excluded from analysis because of equipment failure. Difference scores for each condition were calculated (i.e., comfortable: subtracting the HR in the play period from the HR in the post-holding period; uncomfortable: subtracting the HR in the separation period from the HR in the post-holding period). A one-sample $t$-test was conducted for each difference score. Results indicated that for the uncomfortable condition, the difference score was significantly lower than $0(t(19)=-2.72, p=.014, d=0.86)$, but not in the comfortable condition $(t(19)=-.20, p=.85, d=0.06)$ (Figure 3).

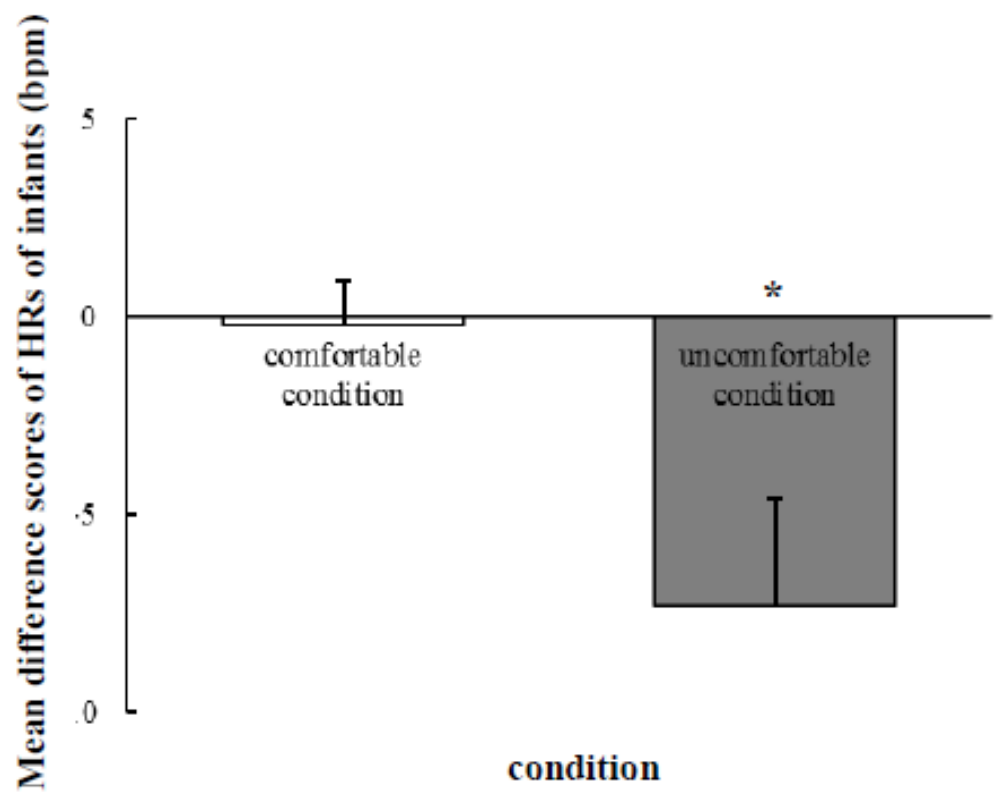

Figure 3. The mean difference scores for HRs of infants in the comfortable and the uncomfortable conditions. Error bars show SE. * $p<.05$. 


\subsubsection{Maternal behaviors in pre-holding periods in the two conditions}

To examine the order effect, we analyzed whether maternal behaviors in pre-holding periods of each condition were similar. Results indicated that the duration of 'tapping' in the pre-holding period of the comfortable condition was significantly longer than in the pre-holding period of the uncomfortable condition (Wilcoxon Test: $z$ $=-2.60, p=.009, r=-.52)$. Moreover, the durations of 'vocalizing' and 'rocking horizontally and quietly' in the pre-holding period of the comfortable condition was significantly shorter than in the pre-holding period of the uncomfortable condition (Wilcoxon Test: $z=-2.57, p=.010, r=-.51$ for 'vocalizing'; $z=-3.16, p=.002, r=$ - .63 for 'rocking horizontally and quietly').

\subsection{Relationship between parenting stress and maternal holding types}

\subsubsection{Parenting stress and durations of subcategories in maternal holding}

We examined the relationship between parenting stress and maternal behaviors in the post-holding period of the two conditions. We focused on maternal behaviors which varied depending on the infants' different emotional states: 'rocking horizontally and quietly' and 'vocalizing' for the comfortable condition, 'grabbing', 'tapping', 'rocking vertically at high frequency' and 'vocalizing' for the uncomfortable condition.

The P-4 (Parental capability) scores and durations of 'vocalizing' in the post-holding period of the comfortable condition were significantly correlated, $r=-.55$, $p=.005$. The P-7 (I can hardly feel affection for my child) scores and durations of 'vocalizing' in the post-holding period of the uncomfortable condition were significantly correlated, Spearman correlation: $r_{s}=-.42, p=.039$. Also the C-4 (The 
child cannot concentrate/is hyperactive) scores and durations of 'vocalizing' in the post-holding period of the uncomfortable condition were significantly correlated, $r=.41$, $p=.041$. However, no significant correlation was found between parenting stress scores and durations of other subcategories.

\subsubsection{Relationship between parenting stress and the frequency of transition of} subcategories of maternal holding

Few mothers changed their behaviors in the Touching category and Holding category (Touching: $n=5$ for the comfortable condition and $n=5$ for the uncomfortable condition; Holding: $n=4$ for the comfortable condition and $n=4$ for the uncomfortable condition; Rocking: $n=18$ for the comfortable condition and $n=20$ for the uncomfortable condition). Therefore, the Touching category and Holding category were excluded from the analyses, and we analyzed only the Rocking category. The relationships between parenting stress and the frequency of transition of subcategories during the post-holding period in both conditions were examined. Only in the uncomfortable condition, the $\mathrm{C}-2$ (The child is in a bad mood) scores and the frequency of transition of subcategories in the Rocking category were significantly correlated, Spearman correlation: $r_{s}=.40, p=.049$ (Figure. 4). 


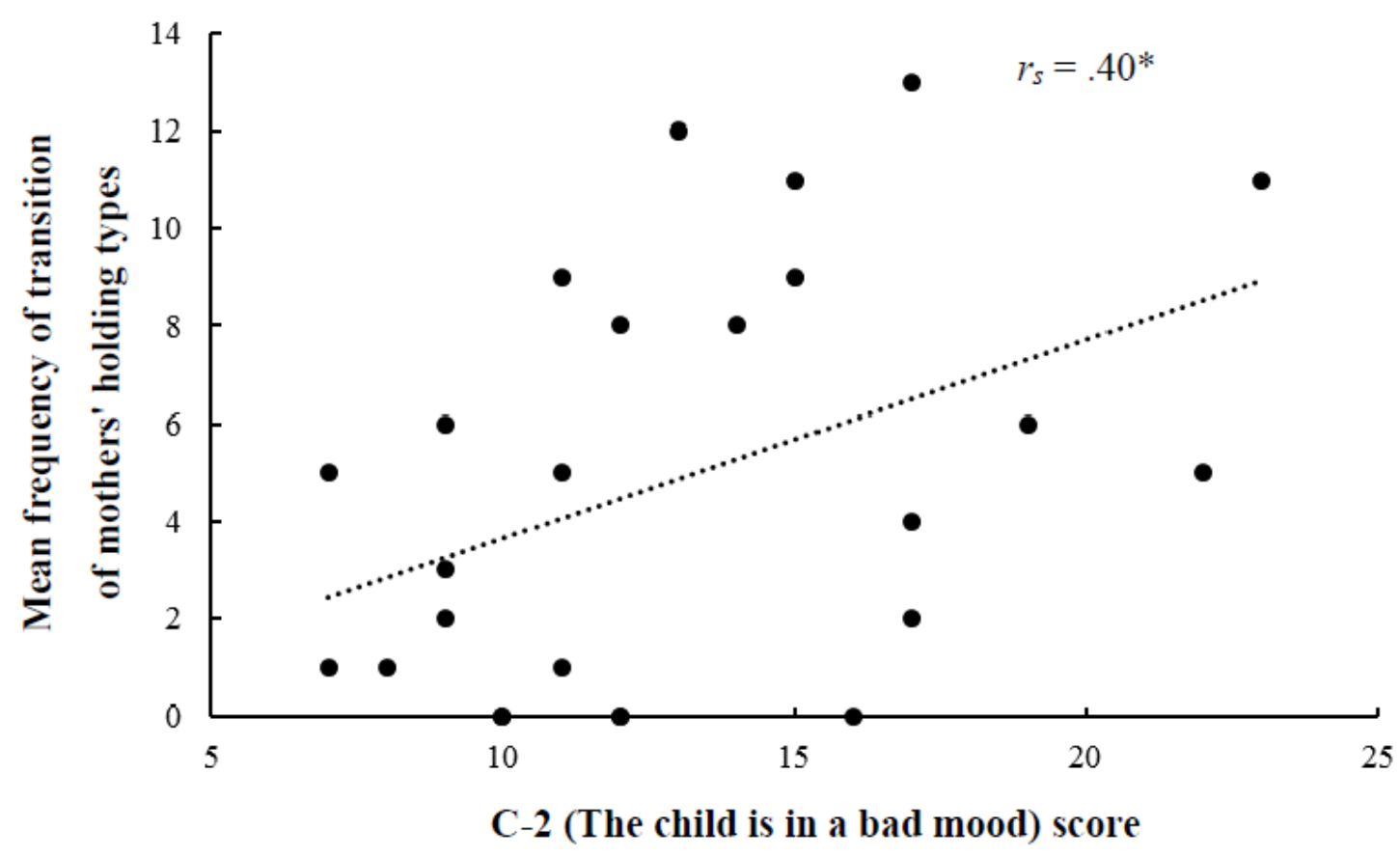

Figure 4. Scatter plots showing the relationship between the C-2 (The child is in a bad mood) scores and the mean frequency of transition of mothers' holding types (Rocking category) in the post-holding period of the uncomfortable condition. ${ }^{*} p<.05$.

\section{Discussion}

The main purpose of this study was to examine whether infants' emotional states influence their mothers' holding behaviors. We manipulated infants' emotional states (positive and negative) by interacting with or being separated from their mothers. To confirm the infants' states, we analyzed their HRs in the baseline phase, the play period and the separation period, and verified that infants' HRs in the separation period of the uncomfortable condition were higher than those in the first baseline period and the play period in the comfortable condition. The increase in infants' HRs reflects their fearful or anxious state (Campos, Emde, Gaensbauer, \& Henderson, 1975), so the current findings 
can be interpreted as showing that infants were more uncomfortable in the separation period of the uncomfortable condition than in the first baseline period and the play period of the comfortable condition.

The most important finding of the present study is that mothers varied their types of holding behaviors depending on their infants' emotional states. When infants were comfortable or calm, their mothers spent much time rocking them horizontally and quietly, and frequently vocalized to their infants during holding. These findings are inconsistent with the results of Aso and Iwatate (2006), which found that mothers used strong physical stimulation, such as roughly rocking in a playing context. However, in the present study, the infants might be calm instead of active since the infants' HRs in the play period (comfortable condition) were not significantly higher than in the baseline period. This may be why strong physical stimulation was not observed during the play period in our study. Moreover, Byrne and Horowitz (1981) suggested that a drowsy state of infants is induced by horizontal rocking, but not by vertical rocking. For these reasons, the mothers in our study might use 'rocking horizontally and quietly' to continue calming their infants. In fact, infant HRs did not change from the play period to the post-holding period in the comfortable condition. This suggests that mothers might be able to keep their infants in a calm state. Regarding 'vocalizing', mothers may use this type of parenting behaviors as an effective way in a holding context for keeping their infants calm. On the other hand, when infants were uncomfortable, their mothers increased the time spent rocking their infants vertically at a high frequency during holding. Vrugt and Pederson (1973) stated that higher frequency rocking has an effect of soothing infants. In addition, Byrne and Horowitz (1981) showed that an intermittent form of rocking, particularly vertically rocking, induces a bright-alert state in infants. 
Therefore the mothers in our study might use vertical rocking at a high frequency to change infants' emotional states from negative to positive. Actually, infant HRs decreased from the separation period to the post-holding period in the uncomfortable condition. This suggests infants might recover from a negative emotional state to a neutral or positive emotional state because of this vertical rocking at a high frequency. Whether their infants are comfortable or uncomfortable, mother might empirically learn how to deal with their infants. In addition, mothers increased their time spent 'tapping' and 'vocalizing' and decreased their time spent 'grabbing' when infants were uncomfortable. These changes appear to be plausible, since Jahromi, Putnam and Stifter (2004) reported that mothers tapped infants and vocalized while holding them to soothe infants who were crying. We are unable to discuss 'grabbing' in our study since it was rarely observed during the pre- and post-period in the uncomfortable condition.

Another key finding in the current study is that some types of parenting stress were related to specific maternal behaviors in the context of holding. In this study, mothers feeling more stress related to parental capability vocalized less frequently in the post-holding period in the comfortable condition. Also, in the uncomfortable condition, mothers with higher stress relating to difficulty in feeling affection for their infants vocalized less frequently in the post-holding period. A prior study has suggested that depressed mothers interact less frequently with their infants (Paulson et al., 2006). Moreover, Teti and Gelfand (1991) indicated that maternal competence and maternal depression were negatively correlated. Also, Righetti-Veltema, Bousquet, and Manzano (2003) showed that mothers with postpartum depressive symptoms were less affectionate. Thus, mothers who feel less confident about their own parenting ability and feel less affection for their infants might interact less with their infants. As a result, 
such mothers might vocalize less to their infants.

On the other hand, mothers who feel more stress about their infants' hyperactivity or difficulty concentrating vocalized more frequently in the post-holding period in the uncomfortable condition. Also, mothers feeling more stress due to the bad mood of their infants tended to change their holding behaviors more frequently, especially Rocking category behaviors. Maternal vocalization can attract the infant's attention and soothe them during holding (Jahromi et al., 2004; Stevenson, ver Hoeve, Roach, \& Leavitt, 1986). Also, rocking is effective to soothe infants (Esposito et al., 2013; Jahromi et al., 2004; Vrugt \& Pederson, 1973). Therefore, when infants were distressed or uncomfortable, mothers feeling stress about their infant's negative disposition might desperately try to interact with or soothe their infants to reduce their own stress, and then such mothers might vocalize more or rock their infants in several different ways.

The findings of this study are constrained by certain limitations. The order of the two conditions, comfortable and uncomfortable conditions, was fixed. Examining for possible order effects indicated significant differences in 'tapping', 'vocalizing' and 'rocking horizontally and quietly' in pre-holding periods of each condition, which is suggestive of order effects. In regards to 'tapping', the duration of 'tapping' increased significantly from the pre-holding period to the post-holding period of the uncomfortable condition, whereas there was no significant difference in the duration of 'tapping' between pre- and post-holding periods of the comfortable condition. The comparison between pre-holding periods of the two conditions suggested an order effect (the effect of the comfortable condition, passed time, or habituation to the experimental situation). However, the increase in the duration of 'tapping' of the uncomfortable condition was considered to be caused changes in infants' emotional states. Therefore, 
we concluded that the significant difference between pre- and post-holding periods of the uncomfortable condition was due to the effect of the condition. In regards to 'vocalizing', the duration of 'vocalizing' increased significantly from the pre-holding to the post-holding periods of comfortable and uncomfortable conditions. Although there is an order effect between pre-holding periods of both conditions, there are also effects of each condition. Therefore, we concluded that the significant difference between preand post-holding periods of the uncomfortable condition was due to the effect of the condition. In regards to 'rocking horizontally and quietly', the duration of 'rocking horizontally and quietly' of the comfortable condition increased significantly from the pre-holding to the post-holding period. However the duration of 'rocking horizontally and quietly' of the uncomfortable condition in the post-holding period was not different from that of the pre-holding period. Therefore, it is possible that this behavioral duration of the uncomfortable condition did not increase because of a ceiling effect. But we believe that there was enough room for this behavior to increase, because the duration of 'rocking vertically at high frequency' was mutually exclusive from 'rocking horizontally and quietly,' which increased significantly from the pre-holding to the post-holding period of the uncomfortable condition. Thus it is unlikely that no increase in the duration of 'rocking horizontally and quietly' in uncomfortable condition is due to the ceiling effect by an order effect.

In summary, infants' emotional states and mothers' parenting stress affect their mothers' holding behaviors. Mothers use horizontal and quiet rocking when infants are comfortable. On the other hand, when infants are uncomfortable, mothers use vertical and frequent rocking behaviors. Furthermore, some types of parenting stress relate to several types of maternal behaviors during holding. In this study, we examined only 
how infants influenced maternal holding behaviors. Maternal holding behaviors influenced by the infants must also influence the infants' behaviors and emotional states. These mutual or contingent influence dynamics of mother-infant interactions in holding need to be investigated further in future research. 


\section{Acknowledgements}

We thank H. Fukuyama for his help in data collection and his comments on earlier drafts of this paper. The research reported here was supported by Grants-in-Aid for Scientific Research from the Japan Society for the Promotion of Science and the Ministry of Education Culture, Sports, Science and Technology (24300103, 24119005), and ERATO, Okanoya Emotional Information Project, Japan Science and Technology Agency. 


\section{References}

Abidin R.R. (1995). Parenting Stress Index: Professional Manual. Psychological Assessment Resources, FL, USA.

Aso, N., \& Iwatate, S. (2006). Differences in mothers' touching their infants who were 0-1 year old among the seven scenes of nurturing: Using the retrospective method. Journal of Child Health, 65, 488-497 (in Japanese with English summary).

Byrne, J. M., \& Horowitz, F. D. (1981). Rocking as a soothing intervention: The influence of direction and type of movement. Infant Behavior \& Development, 4, 207-218. doi: 10.1016/S0163-6383(81)80024-0

Byrt, T., Bishop, J., \& Carlin, J. B. (1993). Bias, prevalence and kappa. Journal of Clinical Epidemiology, 46, 423-429. doi: 10.1016/0895-4356(93)90018-V

Campos, J. J., Emde, R. N., Gaensbauer, T., \& Henderson, C. (1975). Cardiac and behavioral interrelationships in the reactions of infants to strangers. Developmental Psychology, 11, 589-601. doi: 10.1037/0012-1649.11.5.589

Cogill, S. R., Caplan, H. L., Alexandra, H., Robson, K. M., \& Kumar, R. (1986). Impact of maternal postnatal depression on cognitive development of young children. British Medical Journal, 292, 1165-1167. doi: 10.1136/bmj.292.6529.1165

Esposito, G., Yoshida, S., Ohnishi, R., Tsuneoka, Y., Rostagno, M. C., Yokota, S., Okabe, S., Kamiya, K., Hoshino, M., Shimizu, M., Venuti, P., Kikusui, T., Kato, T., \& Kuroda, K. O. (2013). Infant calming responses during maternal carrying in humans and mice. Current Biology, 23, 739-745. doi: 10.1016/j.cub.2013.03.041

Ferber, S. G. (2004). The nature of touch in mothers experiencing maternity blues: The contribution of parity. Early Human Development, 79, 65-75. doi: 
10.1016/j.earlhumdev.2004.04.011

Ferber, S. G., Feldman, R., \& Makhoul, I. R. (2008). The development of maternal touch across the first year of life. Early Human Development, 84, 363-370. doi: 10.1016/j.earlhumdev.2007.09.019

Feldman, R., Eidelman, A. I., Sirota, L., \& Weller, A. (2002). Comparison of skin-to-skin (kangaroo) and traditional care: Parenting outcomes and preterm infant development. Pediatrics, 110, 16-26.

Gray, L., Watt, L., \& Blass, E. M. (2000). Skin-to-skin contact is analgesic in healthy newborns. Pediatrics, 105, e14.

Hanada, H., Honda, S., Tokumaru, T., \& Ozawa, H. (2006). Association between mothers' concern about child rearing and their parenting stress. Acta medica Nagasakiensia, 51, 115-120.

Jahromi, L. B., Putnam, S. P., \& Stifter, C. A. (2004). Maternal regulation of infant reactivity from 2 to 6 months. Developmental Psychology, 40, 477-487. doi: $10.1037 / 0012-1649.40 .4 .477$

Jean, A. D. L., \& Stack, D. M. (2009). Functions of maternal touch and infants' affect during face-to-face interactions: New directions for the still-face. Infant Behavior \& Development, 32, 123-128. doi: 10.1016/j.infbeh.2008.09.008

Lewis, M., \& Feiring, C. (1989). Infant, mother, and mother-infant interaction behavior and subsequent attachment. Child Development, 60, 831-837.

Malphurs, J. E., Raag, T., Field, T., Pickens, J., \& Pelaez-Nogueras, M. (1996). Touch by intrusive and withdrawn mothers with depressive symptoms. Early Development \& Parenting, 5, 111-115. doi: 10.1002/(SICI)1099-0917(199606)5:2<111::AID-EDP122>3.3.CO;2-R 
Murray, L., Fiori-Cowley, A., Hooper, R., \& Cooper, P. (1996). The impact of postnatal depression and associated adversity on early mother-infant interactions and later infant outcome. Child Development, 67, 2512-2526. doi: 10.1111/j.1467-8624.1996.tb01871.x

Narama, M., Kanematsu, Y., Araki, A., Maru, M., Nakamura, N., Takeda, J., Shirahata, N., \& Kudo, Y. (1999). Validity and reliability of the Japanese version of the Parenting Stress Index. Journal of Child Health, 58, 610-616 (in Japanese).

Negayama, K., Kawai, M., Yamamoto, H., Tomiwa, K., Sakakihara, Y., \& Japan Children's Study Group. (2010). Behavioral development of infant holding and its laterality in relation to mothers' handedness and child-care attitude. Infant Behavior \& Development, 33, 68-78. doi: 10.1016/j.infbeh.2009.11.001

Paulson, J. F., Dauber, S., \& Leiferman, J. A. (2006). Individual and combined effects of postpartum depression in mothers and fathers on parenting behavior. Pediatrics, 118, 659-668. doi: 10.1542/peds.2005-2948

Reddy, V., Markova, G., \& Wallot, S. (2013). Anticipatory adjustments to being picked up in infancy. PLOS ONE, 8, e65289. doi: 10.1371/journal.pone.0065289

Righetti-Veltema, M., Bousquet, A., \& Manzano, J. (2003). Impact of postpartum depressive symptoms on mother and her 18-month-old infant. European Child \& Adolescent Psychiatry, 12, 75-83. doi: 10.1007/s00787-003-0311-9

Saijo, T., \& Negayama, K. (2001). A study on the development of styles of holding infants and their infants -Active participation according to their positions-. Journal of Child Health, 60, 82-90 (in Japanese).

Stack, D. M., \& Muir, D. W. (1992). Adult tactile stimulation during face-to-face interactions modulates five-month-olds' affect and attention. Child Development, 
63, 1509-1525. doi: 10.1111/j.1467-8624.1992.tb01711.x

Stevenson, M. B., Ver Hoeve, J. N., Roach, M. A., \& Leavitt, L. A. (1986). The beginning of conversation: Early patterns of mother-infant vocal responsiveness. Infant Behavior \& Development, 9, 423-440. doi: 10.1016/0163-6383(86)90016-0

Teti, D. M., \& Gelfand, D. M. (1991). Behavioral competence among mothers of infants in the first year: The mediational role of maternal self-efficacy. Child Development, 62, 918-929. doi: 10.1111/j.1467-8624.1991.tb01580.x

Væver, M. S., Krogh, M. T., Smith-Nielsen, J., Harder, S., \& Køppe, S. (2013). Measuring spatial proximity in mother-infant interaction: A kinematic approach for an examination of the effects of maternal postpartum depression. Infant Behavior \& Development, 36, 427-431. doi: 10.1016/j.infbeh.2013.03.007

Vrugt, D. T., \& Pederson, D. R. (1973). The effects of vertical rocking frequencies on the arousal level in two-month-old infants. Child Development, 44, 205-209. doi: 10.1111/j.1467-8624.1973.tb02139.x

Weiss, S. J., Wilson, P., Hertenstein, M. J., \& Campos, R. (2000). The tactile context of a mother's caregiving: Implications for attachment of low birth weight infants. Infant Behavior \& Development, 23, 91-111. doi: 10.1016/S0163-6383(00)00030-8 